\title{
A Study to Evaluate the Knowledge and Awareness amongst Dental Professionals about COVID-19 Outbreak - A Survey
}

\author{
Omkar Santosh Sakpal ${ }^{1}$, Shivsagar Tewary ${ }^{2}$, Pronob Sanyal ${ }^{3}$ \\ 1,2,3 Department of Prosthodontics and Crown \& Bridge, School of Dental Sciences, \\ KIMS-DU, Karad, Maharashtra, India.
}

\section{ABSTRACT}

\section{BACKGROUND}

Across the globe, there have been reports which have shown that all the dental professionals and the field of dentistry to be more vulnerable to the coronavirus infection. Dentists in general are comparatively more prone to infections as they are more exposed to aerosols and droplets emerging out of the patient's oral cavity. This scare of coronavirus has unmasked the crevices in the integration of the dental health care professionals in to the public health care sector of various countries. It has significantly sidelined the dental treatment approach towards the patients and for the dental team as well. At this point, it is very difficult to project and calculate the exact number of cases of Covid-19 carriers or infected who are being treated by dentists. Such a preliminary survey will give us an idea about the precautionary measures that can be taken or being taken in dental practice. The aim of the study was to assess the knowledge, attitude and practice amongst dental professionals of different specialties about the Covid-19 and precautionary measures at different levels.

\section{METHODS}

An online questionnaire based survey was carried out to assess the knowledge, attitude and practice amongst the dental professionals of different specialties about recent Covid 19 pandemic all over the world. A total of 250 participants were sent a survey questionnaire via Google Survey form. The responses were accepted in a 2 week time frame. The survey majorly focused on the clinical practice awareness and precautions taken by the dental professionals at their university / institute / college / private clinics while treating their patients based on which their knowledge and awareness were assessed. Demographic characteristics of study participants and their knowledge, awareness and practice related to Covid-19 were presented using descriptive statistics (mean and frequency distribution).

\section{RESULTS}

Two hundred and forty-four (97.6\%) out of 250 participants surveyed responded to the questionnaire. Overall awareness amongst dental professionals was seen to be adequate with maximum correct responses received from the Teaching faculty of different institutes. Regarding the precaution level taken at the respective Institute / College / University the average score calculated on the base of responses was 6.92.

\section{CONCLUSIONS}

The survey concluded that there is a dire need for regular educational interventions regarding the spread of the diseases and infection control at definite intervals. All dental professionals must be well aware of the protection kits available and their appropriate use during patient diagnosis and treatment planning.

\section{KEY WORDS}

Coronavirus, COVID-19 Survey, Dentists, Dental Professionals.
Corresponding Author: Dr. Omkar Santosh Sakpal.

Department of Prosthodontics and Crown \& Bridge, School of Dental Sciences, KIMS-DU, Karad, Maharashtra, India.

E-mail:dromsakpal95@gmail.com

DOI: $10.14260 /$ jemds/2020/699

How to Cite This Article:

Sakpal OS, Tewary S, Sanyal P, et al. A study to evaluate the knowledge and awareness amongst dental professionals about COVID19 outbreak: a survey. J Evolution Med Dent Sci 2020;9(43):3186-3191, DOI: $10.14260 /$ jemds/2020/699

Submission 21-07-2020,

Peer Review 15-09-2020,

Acceptance 22-09-2020,

Published 26-10-2020.

Copyright (C) 2020 Omkar Santosh Sakpal et al. This is an open access article distributed under Creative Commons Attribution License [Attribution 4.0 International (CC $B Y 4.0)]$ 


\section{BACKGROUND}

Dentists are usually exposed to many infectious materials, including body substances and contaminated supplies, equipment, environmental surfaces, water and air. Infection control, one of the most important topics in dentistry, has become such an essential part of the practice to the limit that dental health workers no longer interrogate its necessity.

Recently there has been an outburst of coronavirus disease 2019 (Covid-19) in areas of China (specifically Wuhan) which emerged out speedily into the civic health sector which lead to a severe crisis. It has not only limited its boundaries till Wuhan, China but also has created havoc by its exponential growth in different countries of the planet. ${ }^{1}$ Coronavirus, in peculiar exists in the group of single-stranded RNA viruses, Coronaviridae. ${ }^{2}$ They belong to the category of zoonotic viruses and are transmitted from animals to humans. They include Severe Acute Respiratory Syndrome Coronavirus (SARS-CoV) which was initially noted in 2002 and the Middle East Respiratory Syndrome Coronavirus (MERS-CoV), in $2012 .^{3}$

On $30^{\text {th }}$ January 2020, the World Health Organization (WHO) affirmed raging escalation of the spread of SARS-CoV 2 and its linked disease (Covid-19) a public health emergency with currently known overall positively infected cases to be $16,19,495$ and 97,039 were declared dead because of this deadly virus (as of April 10, 2020) and this number continued to escalate. Hence effective regulations for prevention, identification and management should be in carried out for appropriate extenuation of further spread. ${ }^{4}$ While in India a total of 6,725 cases have been reported and 229 declared dead (as of April 07, 2020) and it continues to be a major concern. ${ }^{5}$

As the recognition of this pandemic is continuously emerging, dentists should be exceptionally ready to diagnose a patient with suspected Covid-19 infection and then refer such patients to the appropriate treatment centers, be it questionable, confirmed or with history of Covid-19. Utmost precautionary steps need to be taken to spread awareness regarding the preventive measures for dental professionals in their private clinical practices or at institute levels. At this point it is very difficult to project and calculate the exact number of cases of Covid-19 carriers or infected treated by dentists. Such a preliminary survey will give us an idea about the existing precautionary measures that can be taken in dental practice.

Hence, this online survey was performed to evaluate the knowledge, attitude and practice amongst dental professionals of different specialties about Covid-19 and its precautionary measures at different levels.

\section{METHODS}

An Institutional Ethical Committee Clearance (Protocol No.: 379 / 2019-2020; Ref.: KIMSDU / IEC / 04 / 2020) was obtained from the research ethical committee for conducting the online survey after which, a descriptive cross-sectional study was conducted among dental clinicians, postgraduate students (PG), undergraduate students (UG), teaching faculty and interning students practicing and studying all over India and other parts of the world. A questionnaire was designed which focused on knowledge-based questions regarding preventive care options against Covid-19, attitude-based ${ }^{4}$ questions eliciting what the dentists feel about such strategies, and practice-based ${ }^{7}$ questions to judge whether they incorporate these strategies in their daily clinical and institutional dental practice. The questionnaire was a Google doc file consisting of 25 different questions in the English language. The questionnaire designed was face validated by subjecting it to five different experts and was modified as per the reviews and comments received from them. The sociodemographic specifics of each participant included age, gender, year of study, place of study and / or work, their specialization and qualifications respectively. All questions were open ended questions for which the participants were asked to select their preferred opinions regarding the modified adopted clinical practices at their setups and in the institutes.

The questions were circulated amongst the dental professionals and students by different online means and responses were accepted in a 2 week time frame. Two hundred and forty-four responses were received by the end of $2^{\text {nd }}$ week out of 250 participants amongst which the questionnaire was circulated.

\section{Statistical Analysis}

The acquired data was entered and interpreted with the IBM Statistical Package for the Social Sciences (SPSS) Software v20. Demographic characteristics of study participants and their knowledge, awareness and practice related to Covid-19 were presented using descriptive statistics (mean and frequency distribution). Chi Square analysis test was applied for this study. All statistical analyses were carried out at a significance level of $\mathrm{P} \leq 0.05$.

\section{RESULTS}

Two hundred and forty-four out of 250 participants surveyed answered the questionnaire generating the yielding rate of $97.6 \%$. In this study $79(32.4 \%)$ participants were undergraduates; 23 (9.4\%) of them were interning at different colleges; 67 (27.5\%) postgraduates from different branches, $69(28.3 \%)$ clinicians and $6(2.5 \%)$ were teaching faculty. The basic demographic details of the participants are tabulated in (Figure 1).

The novel human coronavirus which is now named SARSCoV-2 emerged in the areas of Wuhan, China in late 2019 which is now considered to be as a pandemic in nature. ${ }^{6} 239$ participants out of 244 could identify the origin of SARS-CoV2 correctly. Evidence of the virus present in humans includes identification in the bronchoalveolar-lavage fluid which is done by genome sequencing, direct Polymerase chain reaction (PCR), and culture. ${ }^{7}$

At University / College / Institute / Clinical level, various opinions were received regarding the screening options available and for the hand rub or sanitizing formulations for the patients visiting the clinical outpatient departments (OPD) described in the graphical representation (Figure 2). 


\begin{tabular}{|c|c|c|c|c|c|c|c|c|c|c|c|}
\hline \multirow{2}{*}{$\begin{array}{l}\text { Treatment } \\
\text { (Answer) }\end{array}$} & \multicolumn{2}{|c|}{ UG's } & \multicolumn{2}{|c|}{ Interns } & \multicolumn{2}{|c|}{ PG's } & \multicolumn{2}{|c|}{$\begin{array}{c}\text { Teaching } \\
\text { Faculty }\end{array}$} & \multicolumn{2}{|c|}{ Clinicians } & \multirow[t]{2}{*}{$\begin{array}{c}\text { p } \\
\text { Value }\end{array}$} \\
\hline & $\%$ & No. & $\%$ & No. & $\%$ & No. & $\%$ & No. & $\%$ & No. & \\
\hline $\begin{array}{l}\text { Dental Implants } \\
\qquad(\mathrm{N})\end{array}$ & 57 & 40 & 65.2 & 11 & 85.1 & 50 & 100 & 05 & 5.5 & 51 & 0.001 \\
\hline $\begin{array}{l}\text { Crown and } \\
\text { Bridges (N) }\end{array}$ & 54.4 & 37 & 78.3 & 11 & 85.1 & 50 & 100 & 05 & 85.5 & 51 & 0.001 \\
\hline $\begin{array}{r}\text { Dentur } \\
\text { Partia }\end{array}$ & 50.6 & 32 & 78.3 & 11 & 83.6 & 49 & 100 & 05 & 2.6 & 50 & 0.001 \\
\hline $\begin{array}{r}\text { Gingival } \\
(\mathrm{N}\end{array}$ & 4 & 27 & 73.9 & 10 & 82.1 & 49 & 100 & 05 & 87 & 52 & 0.001 \\
\hline $\begin{array}{r}\text { Scaling } \\
\text { Plann }\end{array}$ & 8 & 24 & 60.9 & 08 & 80.6 & 48 & 100 & 0 & 81.2 & 48 & 0.001 \\
\hline $\begin{array}{l}\text { End } \\
\text { Treat }\end{array}$ & 73.4 & 12 & 73.9 & 13 & 82.1 & 50 & 66.7 & 04 & 75. & 47 & $\begin{array}{l}0.733 \\
\text { (NS) }\end{array}$ \\
\hline $\begin{array}{r}\text { Cons } \\
\text { Restor }\end{array}$ & 48.1 & 10 & 73.9 & 14 & 80.6 & 47 & 100 & 05 & 81.2 & 49 & 0.001 \\
\hline $\begin{array}{r}\text { hird Mole } \\
\text { (Y) }\end{array}$ & & 09 & 87 & 18 & 64.2 & 40 & 66.7 & 03 & 73.9 & 43 & $\begin{array}{l}0.177 \\
\text { (NS) }\end{array}$ \\
\hline $\begin{array}{r}\text { Aes } \\
\text { Proce }\end{array}$ & 54.4 & 01 & 78.3 & 15 & 86.6 & 51 & 83.3 & 05 & 87 & 52 & 0.001 \\
\hline Ex & 3.4 & 07 & 69.6 & 15 & 70.1 & 40 & 83.3 & 04 & 63.8 & 1 & $\begin{array}{l}0.699 \\
\text { (NS) }\end{array}$ \\
\hline $\begin{array}{r}\text { Ortl } \\
\text { Treat }\end{array}$ & 4.4 & 07 & 78.3 & 16 & 88.1 & 52 & 100 & 05 & 87 & 52 & 0.0 \\
\hline $\begin{array}{c}\text { Paediatric } \\
\text { Endodontics }(\mathrm{Y})\end{array}$ & 65.8 & 04 & 56.5 & 09 & 50.7 & 32 & 50 & 02 & $4 / .8$ & 30 & $\begin{array}{c}0.219 \\
(\mathrm{NS})\end{array}$ \\
\hline Pulpotomy (Y) & 70.9 & 03 & 65.2 & 10 & 50.7 & 24 & 83.3 & 04 & 52.2 & 33 & $0.047 *$ \\
\hline
\end{tabular}

\begin{tabular}{|c|c|c|c|c|c|}
\hline & $\mathbf{N}$ & Min. & Max. & Mean & S.D. \\
\hline $\begin{array}{c}\text { On the scale of } 1 \text { - } 10 \text { what level of Precautions } \\
\text { are taken by your Institute / College / } \\
\text { University / Clinic? }\end{array}$ & 244 & 1 & 10 & 6.92 & 2.521 \\
\hline $\begin{array}{l}\text { After being Infected, duration after which the } \\
\text { Symptoms Appear? (in days) }\end{array}$ & 244 & 2 & 21 & 12.21 & 3.847 \\
\hline Valid N (list wise) & \multicolumn{5}{|l|}{244} \\
\hline \multicolumn{6}{|c|}{$\begin{array}{l}\text { Table 2. Descriptive Statistics Regarding the Level of Precautions } \\
\text { Taken by Dental Professionals in Their Clinical Practices and } \\
\text { Knowledge about the Duration after Which Symptoms Occur }\end{array}$} \\
\hline
\end{tabular}

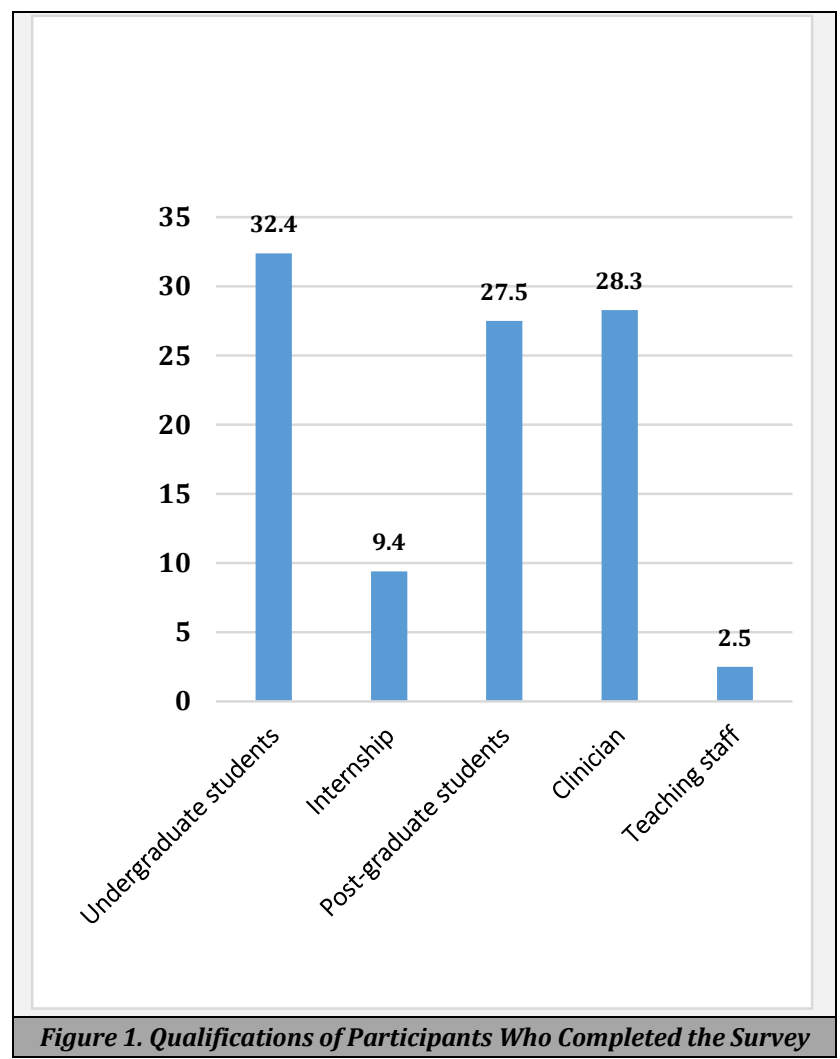

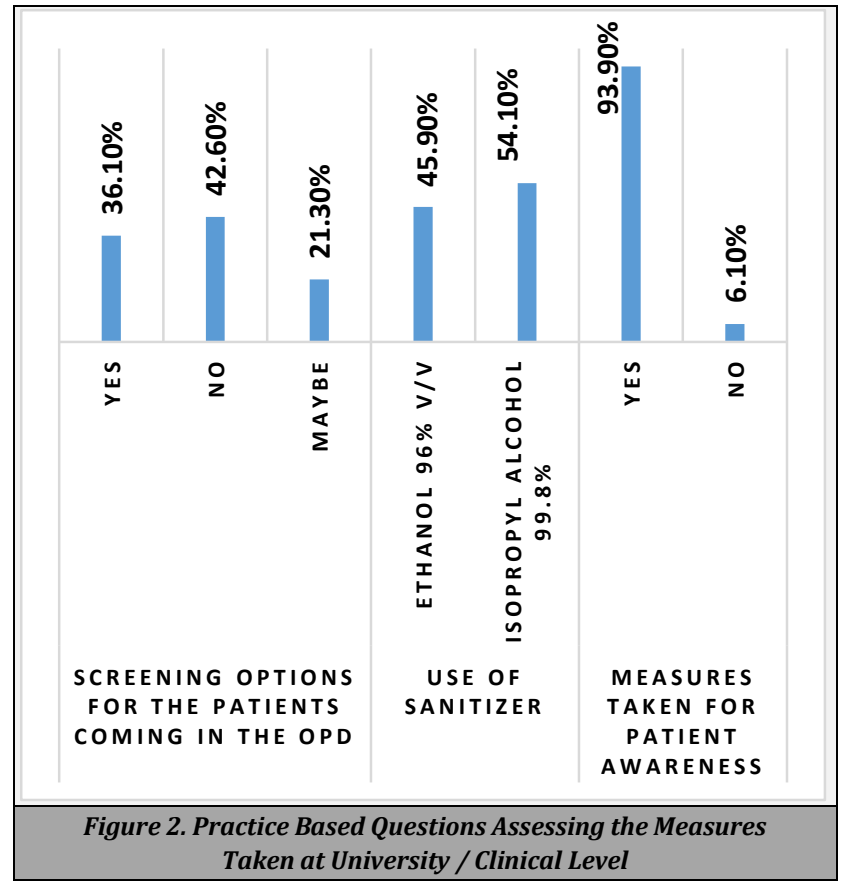

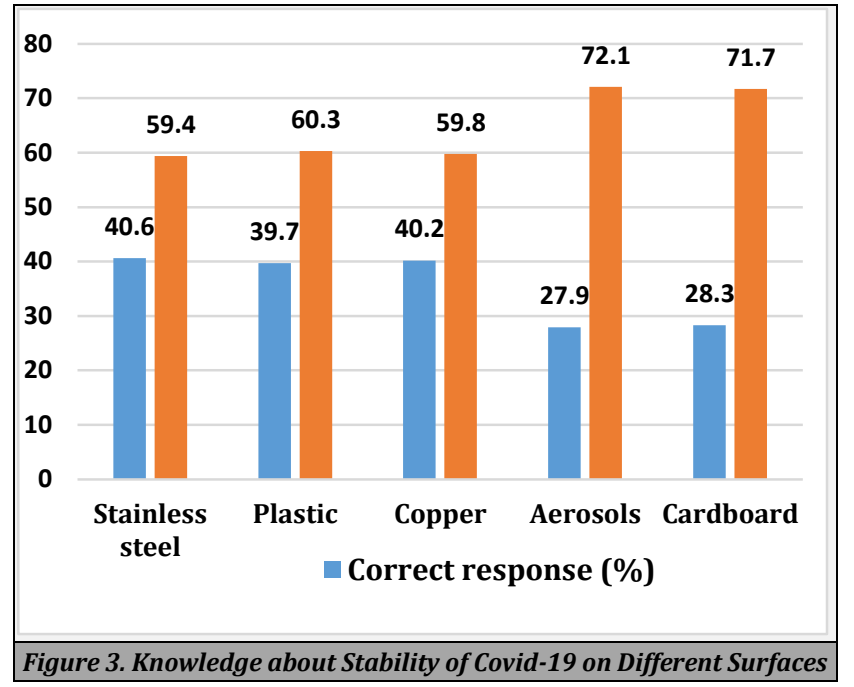

When asked about the emergency essential treatments included such as dental implants, crowns and bridges, complete and partial dentures, gingival surgeries, periodontal procedures, aesthetic, conservative and endodontic procedures, third molar pain and extractions, and paediatric endodontic procedures in their clinical practice the results that were calculated as per the responses are as follows (Table 1).

Regarding the levels of precautions taken at the respective Institute / College / University the average score calculated on the base of responses was 6.92. When asked about the period (in days) in which symptoms start appearing the average days calculated from the responses were 12 days (Table 2).

Regarding the use of personal protection (PPE) kits and disinfecting the Airotor handpieces and as to when do participants believe in changing masks for every patient; the representation of the data is presented graphically (Figure 4). 


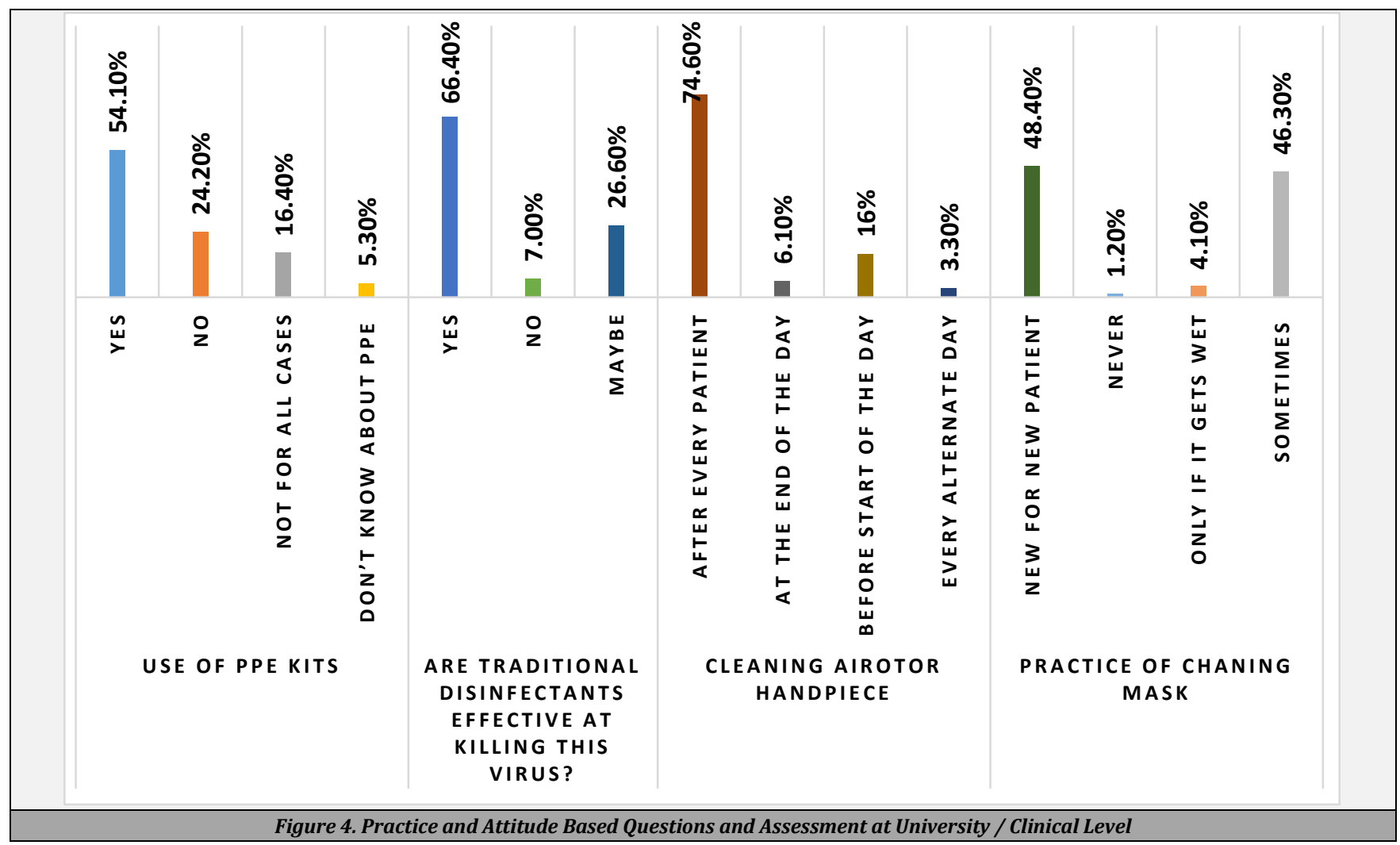

\section{DISCUSSION}

On February $11^{\text {th }}, 2020$ the World Health Organization (WHO) identified the disease as a novel coronavirus which was first identified in Wuhan, China. It derived its name Covid-19 with the following abbreviations 'CO' denotes 'corona,' 'VI' denotes 'virus,' and 'D' denotes disease which was initially referred to as "2019 novel coronavirus" or "2019-nCoV" and the main causative agent for Corona Virus being SARS-CoV-2. ${ }^{8}$

Instructions and ground rules for droplet and airborne isolation prevention are mainly refined to prevent transmission of aerosols containing infectious materials from patients towards dental health professionals. Microbial threats have continued to evolve, remerge and remain. Severe acute respiratory syndrome, or SARS, is the recent contribution to these virulent assortments of threatening diseases recently which is commonly known as coronavirus disease 2019 (Covid-19). They were first identified in humans in the mid-1960s. ${ }^{9}$

A similar study experimented previously in Hong Kong which evaluated the knowledge and attitude of dental patients towards SARS during its. ${ }^{10}$ Another questionnaire study was carried out by Modi P D et. al. ${ }^{11}$ which assessed the awareness of medical health care professionals in Mumbai metropolitan region which showed a decent awareness (71.2\%) amongst the participants and also confirmed that there was a strong need to implement perioding educational interventions and training programs on infection control practices. ${ }^{11}$ To deal with these virulent threats, specifically during pandemics, the dental community has reacted expeditiously by endorsing classic precautionary measures. Dental professionals have been following a systematic infection control protocol to treat dental patients seeking dental care, regardless of their medical histories.
The present study has several key findings. The survey focused on studying 5 groups of participants from the dental profession (undergraduate students, postgraduate students, Interns, teaching faculty, clinicians) for their knowledge, awareness and attitude. Since the Government of India has announced a complete lockdown across the nation majority of the source of information regarding COVID 19 was known through the internet and online sources.

In the present study (Table 2) - $78.5 \%$ of the undergraduate students believed the third molar associated pain, to be the most essential treatment while $46.8 \%$ of students thought scaling and root planing to be the least essential treatment of all. Amongst interns, complete and partial dentures, crowns and bridges, aesthetic procedures and orthodontic treatments were considered to be the least essential treatments (78.3\%) while third molar associated pain was considered to be the highly essential (87 \%) amongst the other treatments. Dental postgraduates from different branches considered orthodontic treatments to be least essential (88.1\%) while endodontic treatments being highly essential (82.1\%) of all mentioned. Orthodontic treatments, crowns and bridges, dental implants, complete and partial dentures, gingival surgeries, conservative restorations and scaling \& root planing were thought to be the least essential $(100 \%)$ treatments while extractions and pulpotomy were considered to be amongst the highly essential (83.3\%) treatments. Clinicians considered endodontic treatments to be the highly essential $(75.4 \%)$ treatments while orthodontic treatments, gingival surgeries and aesthetic treatments to be the least essential (87\%) ones amongst all in their private practices.

Since in the dental clinical setups there are various objects and instrument made up of different materials, the stability of Covid-19 on each of these surfaces play an important role in 
the spread of disease. Scientists have found out that the virus was stable in aerosols for up to three hours, four hours on the copper surfaces, 48 to 72 hours on plastic and stainless-steel surfaces and up to 24 hour survival on cardboard surfaces. ${ }^{12,13}$ In this study the stability of Covid-19 as per the responses was found to be statistically significant only on the cardboard surface. Also, it is advisable to clean the Airotor handpieces if at all being used after every other patient as it is in close contact with patients' oral fluids. In our study $74.60 \%$ of the participants correctly answered the question about cleaning of their Airotor handpieces.

In their guidelines WHO has mentioned hand sanitization formulations for worldwide use and currently alcohol-based rubs are the only known means for efficiently inactivating a wide range of likely harmful viruses on human hands.

These formulations include

1. Ethanol $80 \% \mathrm{v} / \mathrm{v}$, glycerol $1.45 \% \mathrm{v} / \mathrm{v}$, hydrogen peroxide (H2 02) $0.125 \% \mathrm{v} / \mathrm{v}$ diluted in distilled water

2. Isopropyl alcohol $75 \% \mathrm{v} / \mathrm{v}$, glycerol $1.45 \% \mathrm{v} / \mathrm{v}$, hydrogen peroxide $0.125 \% \mathrm{v} / \mathrm{v}$ diluted in distilled water.

N95 respirators are the part of PPE with a pore size of 0.3 microns; commonly used to restrict exposures to infections transmitted via the airborne route, though their effectiveness highly depends on their proper method of use and fitting. The optimal way to prevent airborne transmission is to use a consolidation of interventions from across the hierarchy of controls, not just PPE alone. ${ }^{14}$

For dental professionals as per the guideline's treatments shall be limited to emergency appointments only during the pandemic. These changes benefit faculty and patients' safety, preserve personal protective equipment and patient care supplies, and broaden available health system capacity. If the patient presents with signs or symptoms of respiratory illness, no dental care should be performed temporarily. If applicable, emergency dental care should be delayed unless the patient has revived from the respiratory infection. Avoiding aerosolgenerating procedures like the use of Airotor handpieces and the air-water syringe. Oral Prophylaxis with the ultrasonic scalers is not suggested during this pandemic. Priority should be for minimal invasive restorative techniques being atraumatic with the hand instruments. Regular cleaning and disinfection of the supplies, or equipment located within 6 feet of suspected patients.

Patients with Covid-19 who have concluded their home quarantine can receive emergency dental care which is finalized using two methods: a non-test-based strategy, and a test-based-strategy. ${ }^{15,16}$

- Non-test-based-strategy: At least 72 hours passed since the recovery (resolution of body temperature without the use of fever reducing medications and advancement in respiratory symptoms such as cough or shortness of breath).

- Test-based-strategy: Patients of Covid-19 having symptoms: Resolution of temperature without the use of fever reducing medications.

\section{CONCLUSIONS}

Within the limitations to this survey study the following conclusions were drawn. There is a definite need for the implementation of educational interventions and academic training programs on infection control practices for Covid-19 across dental professionals at regular intervals. The scores for attitude in dental practice in our study may indicate that further education is necessary to boost knowledge amidst dental health professionals. Routine follow up of individuals who are quarantined should be conducted within the facility for the duration of the quarantine period and shall include screening for fever and associated symptoms.

Data sharing statement provided by the authors is available with the full text of this article at jemds.com.

Financial or other competing interests: None.

Disclosure forms provided by the authors are available with the full text of this article at jemds.com.

\section{REFERENCES}

[1] Centers for Disease Control and Prevention. Transmission of coronavirus disease 2019 (COVID - 19). https://www.cdc.gov/coronavirus/2019ncov/about/transmission.html.

[2] Gorbalenya AE, Baker SC, Baric RS, et al. Severe acute respiratory syndrome - related coronavirus-the species and its viruses-a statement of the Coronavirus Study Group. BioRxiv Jan 1, 2020.

[3] Wax RS, Christian MD. Practical recommendations for critical care and anesthesiology teams caring for novel coronavirus (2019 - nCoV) patients. Can J Anaesth 2020;67(5):568-76.

[4] Symptoms of Novel Coronavirus: United States Centers for Disease Control and Prevention (CDC) 2019.

[5] World Health Organization. Coronavirus disease 2019 (COVID-19): $\quad$ situation $\quad 72$. https://coronavirus.jhu.edu/map.html

[6] Coronavirus disease (COVID - 2019) situation reports. Geneva: World Health Organization 2020. https://www.who.int/emergencies/diseases/novelcoronavirus2019/situation - reports/

[7] Zhu N, Zhang D, Wang W, et al. A novel coronavirus from patients with pneumonia in China, 2019. N Engl J Med 2020;382(8):727-33.

[8] Fukuda K, Wang R, Vallat B. Naming diseases: first do no harm. Science 2015;348(6235):643.

[9] Killerby ME, Biggs HM, Haynes A, et al. Human coronavirus circulation in the United States 2014-2017. Journal of Clinical Virology 2018;101:52-6.

[10] Yip HK, Tsang PCS, Samaranayake LP, et al. Knowledge of and attitudes toward severe acute respiratory syndrome among a cohort of dental patients in Hong Kong following a major local out break. Community Dent Health 2007;24(1):43-8.

[11] Modi PD, Nair G, Uppe A, et al. COVID - 19 awareness among healthcare students and professionals in Mumbai metropolitan region: a questionnaire - based survey. Cureus 2019;12(4):e7514. 
[12] van Doremalen N, Bushmaker T, Morris DH, et al. Aerosol and Surface Stability of SARS-CoV-2 as Compared with SARS-CoV-1. N Engl J Med 2020;382(16):1564-7.

[13] Chin AWH, Chu JTS, Perera MRA, et al. Stability of SARS $\mathrm{CoV}-2$ in different environmental conditions. Lancet Microbe 2020;1(1):e10.

[14] Coronavirus disease (COVID - 19) advice for the public: when and how to use masks. https://www.who.int/emergencies/diseases/novel- coronavirus-2019/advice-for-public/when-and-how-touse-masks

[15] Kohn WG, Collins AS, Cleveland JL, et al. Guidelines for infection control in dental health - care settings--2003. MMWR Recomm Rep 2003;52(RR-17):1-61.

[16] Backer JA, Klinkenberg D, Wallinga J. Incubation period of 2019 novel coronavirus (2019 - nCoV) infections among travelers from Wuhan, China, 20-28 January 2020. Euro Surveill 2020;25(5):2000062. 